\title{
Unexpected Relationships between Four Large Deletions in the Human $\beta$-Globin Gene Cluster
}

\author{
Elio F. Vanin, ${ }^{\star \dagger}$ Paula S. Henthorn, ${ }^{\star}$ \\ Dimitris Kioussis, ${ }^{\ddagger}$ Frank Grosveld, ${ }^{*}$ and \\ Oliver Smithies* \\ *Laboratory of Genetics \\ University of Wisconsin \\ Madison, Wisconsin 53706 \\ ‡Laboratory of Gene Structure and Expression \\ National Institute for Medical Research \\ The Ridgeway, Mill Hill \\ London NW7 1AA, England
}

\section{Summary}

Two independent $\gamma \delta \beta$-thalassemias are each associated with large deletions. We show, by comparing DNA sequences, that the deletions are due to nonhomologous DNA exchanges. The $5^{\prime}$ breakpoints are located approximately the same distance apart and in the same order along the DNA as their $3^{\prime}$ breakpoints. Two independent cases of hereditary persistence of fetal hemoglobin, also involving large deletions, show the same unexpected relationship between their $5^{\prime}$ and $3^{\prime}$ breakpoints. This relationship is most simply explained if, within each pair, the deletions are of approximately the same length. The results suggest that the four deletions were generated by a common mechanism. Perhaps their $5^{\prime}$ and $3^{\prime}$ breakpoints are physically close in the nucleus, although far apart on the linear DNA.

\section{Introduction}

The molecular factors predisposing the occurrence of chromosomal rearrangements in higher eucaryotes are rather poorly understood. However, progress has been made in identifying rearrangements that apparently involve exchanges between locally homologous sequences at two different sites. In the human $\beta$-globin gene cluster exchanges of the homologous type have been implicated in the generation of deletions such as $\mathrm{Hb}$ Lepore (Baglioni, 1963; Flavell et al., 1978), duplications such as Hb-Miyada (Ohta et al., 1971), and gene conversions without change in gene copy number such as a conversion between the ${ }^{\mathrm{G}} \gamma$ and ${ }^{\mathrm{A}} \gamma$ globin genes (Slightom et al., 1980). Little is known, however, about the molecular factors involved in chromosomal rearrangements that do not appear to be of the homologous type

There are several rearrangements in the human $\beta$-globin gene cluster for which the stalus with respect to homology at the exchange points has not been determined. The large deletions that have one breakpoint within the cluster and the other in some region well outside are typical of these rearrangements. We describe here our studies of

'Present address: Department of Biochemistry, Ohio State University, Columbus, Ohio 43210. four of these large deletions, carried out in order to gain some insight into the molecular mechanisms underlying their formation. We show that two independent $\gamma \delta \beta$-thalassemias (Van der Ploeg et al., 1980; Orkin et al., 1981; Kan et al., 1972) are each the result of a nonhomologous exchange and that both involve large deletions of DNA, yet the $5^{\prime}$ breakpoints of the two deletions are located approximately the same distance apart and in the same order along the DNA as their respective $3^{\prime}$ breakpoints. Two independent cases of hereditary persistence of fetal hemoglobin, HPFH, (Fritsch et al., 1979; Tuan et al., 1980; Bernards and Flavell, 1980) are similarly shown to result from large deletions and also display the same relationship between their $5^{\prime}$ and $3^{\prime}$ breakpoints. Therefore, within the $\gamma \delta \beta$-thalassemia pair or the HPFH pair approximately the same amount of DNA is deleted. Some possible mechanisms are discussed that could account for these relationships.

In the text that follows, we refer to the exact points in normal DNA at which breakages occur that generate the deletions as the " 5 ' and $3^{\prime}$ breakpoints." The terms $5^{\prime}$ and $3^{\prime}$ are assigned with respect to globin transcription. We use the term "normal $5^{\prime}$ DNA" to describe the DNA in a normal chromosome that encompasses the $5^{\prime}$ breakpoint, and similarly describe "normal $3^{\prime}$ DNA." The point at which normal 5 ' and normal 3' DNA sequences are joined in an affected individual is called the "deletion joint."

\section{Results and Discussion}

Two cases of $\gamma \delta \beta$-thalassemia, referred to below as $\gamma \delta \beta$ thal 1 and $\gamma \delta \beta$-thal 2 , were initially selected for study as examples of large deletions within the human $\beta$-globin gene cluster. $\gamma \delta \beta$-thal 1 was described by Van der Ploeg et al. (1980), who demonstrated that it was the result of a deletion with its $3^{\prime}$ breakpoint approximately $2.5 \mathrm{~kb} 5^{\prime}$ to the adult $\beta$-globin gene (Figure 1). The deletion removes more than $40 \mathrm{~kb}$ of DNA to the $5^{\prime}$ side of this breakpoint, thus removing all the other genes in the $\beta$-globin cluster. $\gamma \delta \beta$-thal 2 was described by Kan et al. (1972) and subsequently studied at the molecular level by Orkin et al. (1981), who demonstrated that the deletion has its $3^{\prime}$ breakpoint in the second coding region of the adult $\beta$ globin gene (Figure 1). This deletion also removes a large amount of DNA (greater than $40 \mathrm{~kb}$ ) to the $5^{\prime}$ side of the breakpoint. In order to determine unequivocally whether these two deletions are due to homologous or nonhomologous exchanges, we needed to compare the nucleotide sequences across the deletion joints with the sequences of the equivalent regions from a normal individual

\section{Isolation of Normal Counterparts of the Deletion Breakpoints}

Cloned DNA sequences spanning the joints of the deletions were already available for both thalassemia cases: the relevant clone from $\gamma \delta \beta$-thal 1 was isolated by Kioussis et al. (1983), while the clone from $\gamma \delta \beta$-thal 2 was isolated 
by Orkin et al. (1981). Cloned normal DNA sequences containing the $3^{\prime}$ breakpoints of the deletions were also available from previous studies of the normal human $\beta$ globin gene cluster (Fritsch et al., 1980). The normal DNAs containing the $5^{\prime}$ breakpoints of the deletions were isolated as follows.

Suitable probes spanning the deletion joints were prepared from the $\gamma \delta \beta$-thal 1 and $\gamma \delta \beta$-thal 2 clones. These probes are labeled 1 and 2 in Figure 1. In each case we showed that the selected fragments did not include significant amounts of repetitive DNA as judged by their lack of hybridization to nick-translated genomic DNA. Probe 1 from $\gamma \delta \beta$-thal 1 was used to screen a phage library made from a partial Eco RI digest of normal human DNA cloned into Charon 4A (Slightom et al., 1980). Four phages were found that hybridized to this probe. Three of these phages also hybridized to probe 3 (see Figure 1 ) which contains the normal $\beta$-globin gene. The fourth phage did not hybridize to probe 3 . This phage was therefore expected to contain the normal $5^{\prime}$ DNA of the $\gamma \delta \beta$-thal 1 deletion and was called NORM.5'. The hybridizing region within the NORM. $5^{\prime}$ phage was found to be confined to a $0.9 \mathrm{~kb}$ Eco Rl fragment within the insert (see Figure 3 below).

For reasons discussed below, we suspected that the normal $5^{\prime}$ sequence corresponding to the other thalassemia deletion, $\gamma \delta \beta$-thal 2 , might also be found in the phage that contains the normal $5^{\prime}$ sequence corresponding to $\gamma \delta \beta$-thal 1. Accordingly, probe 2 , isolated from the clone spanning the $\gamma \delta \beta$-thal 2 deletion (Figure 1), was hybridized to the phage NORM. $5^{\prime}$. Hybridization was detected to a $0.4 \mathrm{~kb}$ Hind III fragment within a $4 \mathrm{~kb}$ Eco Rl fragment (see Figure 3 below).

\section{Nucleotide Sequences across the Deletion Joints and from the Corresponding Normal $5^{\prime}$ and $3^{\prime}$ Regions}

The nucleotide sequences across the deletion joints were determined from the $0.55 \mathrm{~kb}$ Eco Rl-Bam $\mathrm{HI}$ fragment for $\gamma \delta \beta$-thal 1 (= probe 1) and the $0.3 \mathrm{~kb}$ Hind III-Bam HI fragment for $\gamma \delta \beta$-thal 2 (= probe 2, Figure 1). The $0.55 \mathrm{~kb}$ Eco Rl-Bam HI fragment was isolated from a cosmid clone previously reported by Kioussis et al. (1983). The $0.3 \mathrm{~kb}$ Hind III-Bam HI fragment was isolated from a clone reported by Orkin et al. (1981) who also determined some of the sequence spanning the deletion joint. The normal $3^{\prime}$ DNA of the $\gamma \delta \beta$-thal 1 deletion is located between the $\delta$ - and $\beta$-globin genes; its sequence was kindly made available to us by Dr. Richard Spritz (personal communication). The normal $3^{\prime}$ DNA of the $\gamma \delta \beta$-thal 2 deletion is

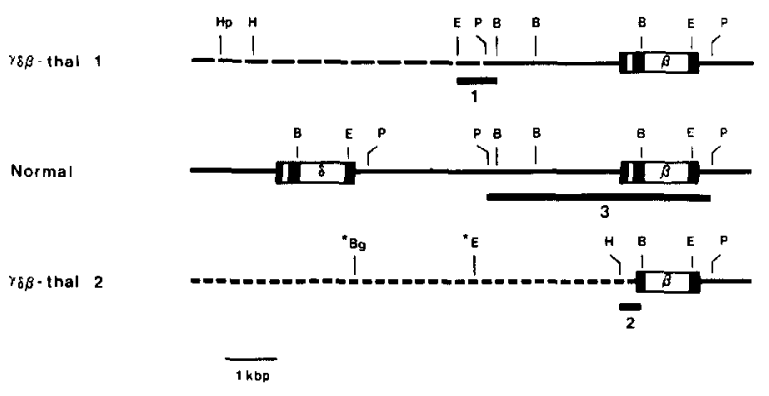

Figure 1. Probes from the Aftected Chromosomes of $\gamma \delta \beta$-Thalassemias 1 and 2 and from the Corresponding Region of a Normal Chromosome

The $\delta$ and $\beta$ genes are shown by rectangles, with the coding regions represented by the solid blocks. The top and bottom lines show the affected chromosomes of the $\gamma \delta \beta$-thal 1 and $\gamma \delta \hat{\delta} \beta$-thal 2 individuals, respectively, while the middle line shows the corresponding region of the normal chromosome. The junctions between dashed lines and solid lines represent deletion joints. The numbered bars under the respective chromosomes indicate three probes; probe 1 is an Eco Rl-Bam $\mathrm{HI}$ fragment, probe 2 is a Hind III-Bam $\mathrm{HI}$ fragment and probe 3 is a Pst I fragment. The asterisks emphasize restriction enzyme sites referred to in the text and in Figure 3 . The restriction enzyme sites are: $\mathrm{B}, \mathrm{Bam} \mathrm{Hl}$; Bg, Bgl Il; E, Eco Rl; H, Hind III; Hp, Hpa I; P, Pst I. Not all sites are diagrammed.

located within the $\beta$-globin gene; its sequence has been determined by Lawn et al. (1980). The normal $5^{\prime}$ DNA sequence of the $\gamma \delta \beta$-thal 1 deletion was determined using the $0.8 \mathrm{~kb}$ Eco Rl fragment of phage NORM.5' described above, and the normal $5^{\prime}$ sequence of the $\gamma \delta \beta$-thal 2 deletion was determined using the $4 \mathrm{~kb}$ Eco Rl fragment of NORM.5'. These six sequences are presented and compared in Figure 2

The sequence data presented in Figure 2 show that in both these $\gamma \delta \beta$-thalassemia cases the deletion was the result of a simple breakage and reunion between the normal $5^{\prime}$ and $3^{\prime}$ DNAs. The normal $5^{\prime}$ sequence and the sequence on the $5^{\prime}$ side of the deletion joint are identical up to, but only up to, the point at which the sequence on the $3^{\prime}$ side of the deletion joint becomes identical to the normal $3^{\prime}$ sequence. There is no indication of any significant homology between the normal $5^{\prime}$ and $3^{\prime}$ sequences for either of the two thalassemia cases. Computer searches at various levels of stringency failed to reveal homology between the normal 5' and 3' sequence pairs presented in Figure 2 at more than the level expected from random sequences of the same nucleotide compositions. For example, randomly scrambling one of the sequences did not alter the level of homology. Therefore we conclude that both these $\gamma \delta \beta$-thalassemia deletions were generated by an exchange involving a nonhomologous breakage and reunion event.

Figure 2. Sequences across the Deletion Joints of $\gamma \delta \beta$-Thalassemias 1 and 2 and of the Corresponding Normal $5^{\prime}$ and $3^{\prime}$ DNAs

For both $\gamma \delta \beta$-thal 1 (A) and $\gamma \delta \beta$-thal 2 (B) three sequences, normal $5^{\prime}$ sequence (top line), deletion joint (middle line), and normal $3^{\prime}$ sequence (bottom line) are aligned without gaps. Dots are placed above the three sequences every 10 base pairs as an aid in counting. An interrupted vertical line between sequences indicates positions at which the sequences are identical. The solid bar above the normal $5^{\prime}$ sequence for $\gamma \delta \beta$-thal 1 overlines the Alu family sequence with the dashed bars indicating the direct repeats flanking the Alu family sequence (Pan et al., 1981). The asterisks above the sequence emphasize the AATAAA hexanucleotide discussed in the text. The sequence of the normal $3^{\prime}$ DNA in (A) is from R. Spritz (personal communication) and the sequence in (B) is from Lawn et al., 1980. Some of the sequence across the deletion breakpoint in (B) was previously determined by Orkin et al. (1981). 
A.

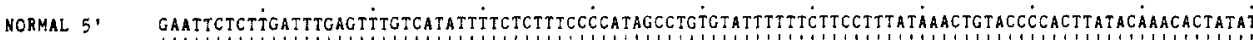
DELETION

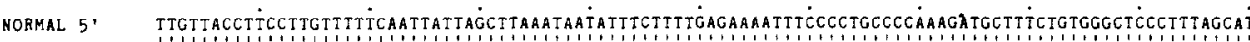

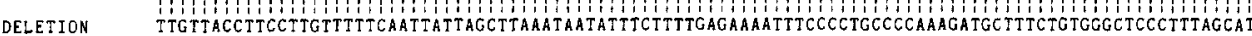

NORMAL $5^{\text {, }}$ DELETION NORMAL $3^{\prime}$

NORMAL 5 , DELETION NORMAL 3 '

NORMAL $5^{\circ}$ DELETION NORMAL 3 ,

NORMAL 5 ' DELETION NORMAL 3 .

NORMAL 5 '

NORMAL 5 ,

B.

NORMAL 5 "

NORMAL 5 '

NORMAL 5 ,

NORMAL 5 , DELETION

NORMAL 3 .

NORMAL 5 , DELETION

NORMAL 3 .

NORMAL 5 , DELETION

NORMAL $3^{\circ}$

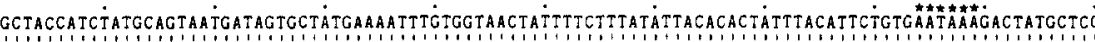

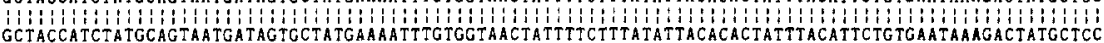

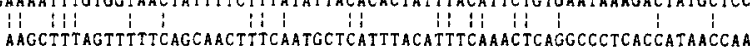

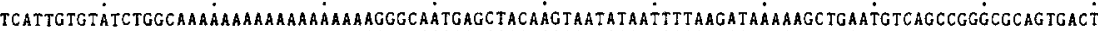

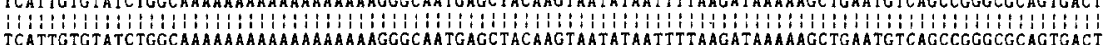

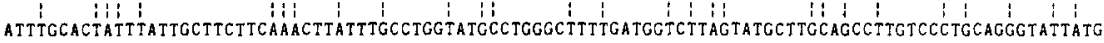

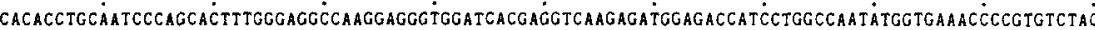
CACACCTGCAATCCCAGTCTGCGTTACACTCTAGTCACACTAAGTAACTRCCATTGGAAAGCAACCCCTGCCTTGAAGCCAGGATGATGCTATCTGCAC

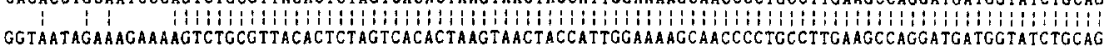

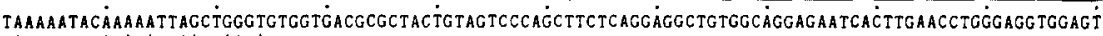

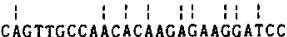

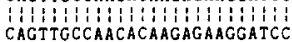

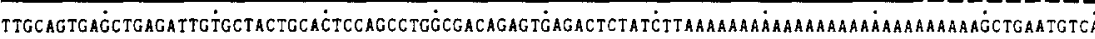

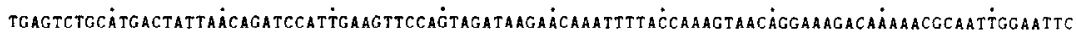

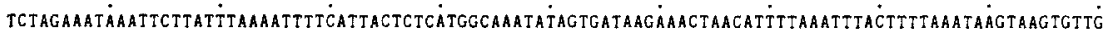

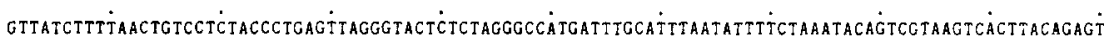

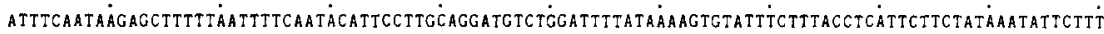

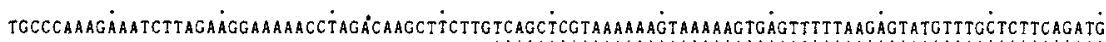

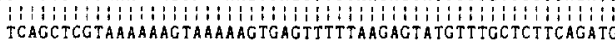
AGACCAATAGAAACTGGOCATGTGGAGACAGAGAAGACTCTIGGGTTTCTGATAGG

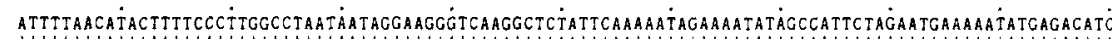

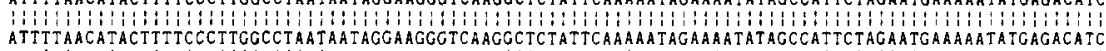

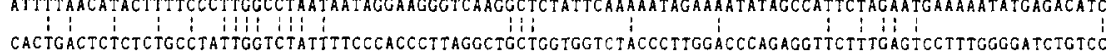

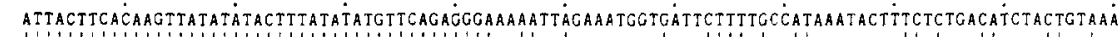

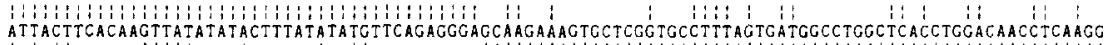

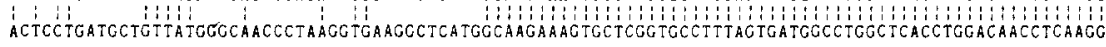

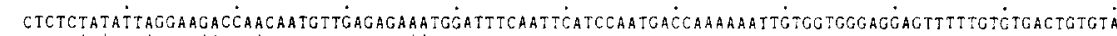

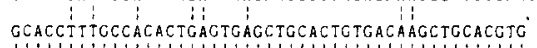

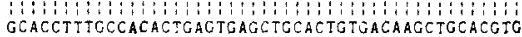




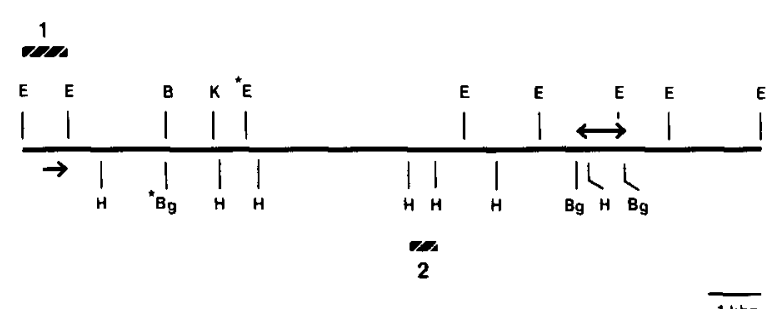

Figure 3. Restriction Enzyme Sites of the Insert DNA of NORM. $5^{\prime}$

The restriction enzyme map of the $14 \mathrm{~kb}$ human insert from the phase NORM. $5^{\prime}$ (see text) is shown. The numbered dashed bars indicate the fragments to which the respective probes (see Figure 1 and text) hybridized. The single-headed arrow indicates the Alu sequence referred to in the text. A double-headed arrow indicates the region in which a second Alu sequence of undetermined orientation is located. The asterisks emphasize restriction enzymes sites referred to in the text and similarly emphasized in

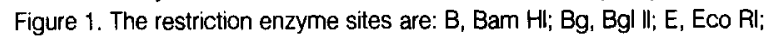
$\mathrm{H}$, Hind III; K, Kpn I.

We inspected the normal $5^{\prime}$ and $3^{\prime}$ sequences of both deletions for any features that might indicate how they came to be involved in the nonhomologous breakage and reunion exchanges. We found that the normal $5^{\prime}$ sequences were somewhat $A+T$ rich: $61 \% A+T$ for $\gamma \delta \beta$ thal 1 and $66 \%$ for $\gamma \delta \beta$-thal 2 , but we do not attach any significance to this because similar percentages are seen in other noncoding regions of the $\beta$-globin complex, and the overall composition of the human genome is approximately $60 \% \mathrm{~A}+\mathrm{T}$.

Further inspection of the normal $5^{\prime}$ and $3^{\prime}$ sequences near the breakpoints showed that the $5^{\prime}$ breakpoint of $\gamma \delta \beta$-thal 1 occurs $31-33$ bp $3^{\prime}$ to the start of an Alu family repeat (Jelinek et al., 1980; Deininger et al., 1981; see Figure 3). The start of an Alu sequence has been defined as the RNA polymerase III transcription initiation point (Duncan et al., 1981) which has been found to occur immediately $3^{\prime}$ to the end of the direct repeat characteristically flanking Alu sequences (Pan et al., 1981). Our failure to observe any hybridization of nick-translated human DNA to the probe 1 is probably a consequence of the short length of Alu sequence remaining after the deletion. No Alu sequence was found associated with the $\gamma \delta \beta$-thal 2 deletion.

Three other deletions within globin gene clusters have been described that have their $5^{\prime}$ breakpoints within an Alu family repeat: HPFH 1 (Jagadeeswaran et al., 1982); a $\delta \beta$-thalassemia (Ottolenghi and Giglioni, 1982); and an $\alpha$ thalassemia (Orkin and Michelson, 1980). The $5^{\prime}$ breakpoint of the HPFH 1 deletion is 113 nucleotides into the $5^{\prime}$ Alu family sequence of the pair of oppositely oriented repeats on the $5^{\prime}$ side of the $\delta$-globin gene (Jagadeeswaran et al., 1982). The $5^{\prime}$ breakpoint of the $\delta \beta$-thalassemia is about 8 nucleotides into the $3^{\prime}$ Alu family repeat of the same pair (Ottolenghi and Giglioni, 1982). Inspection of the sequence $5^{\prime}$ to the deletion joint in one deletion form of $\alpha$-thalassemia (Orkin and Michelson, 1980; S. Orkin, personal communication) shows that its $5^{\prime}$ breakpoint is 96 nucleotides into an Alu family sequence, as initially noted by Jagadeeswaran et al. (1982). In all three cases, as in the $\gamma \delta \beta$-thal 1 case reported here, the deletions do not reform another complete Alu repeat, so that these three deletions also appear to be due to nonhomologous exchanges.

Excluding cases thought to be due to homologous exchange and including all the cases mentioned or reported here, we know of 11 deletions that have at least one breakpoint within the human $\beta$-globin gene cluster (Gilman et al., 1983; Tuan et al., 1983; Ottolenghi and Giglioni, 1982; Jagadeeswaran et al., 1982; Henthorn, unpublished results; Jones et al., 1981a, 1981b). Three breakpoints are within an Alu sequence; 16 are not; three have not been determined. Alu family sequences comprise about $3 \%$ of the human genome (Houck et al., 1979) and about $5 \%$ of the human $\beta$-globin locus, so that breakpoints of deletions would be expected to occur within these sequences within the range of one time in 33 to one time in 20 if the breakpoints and the Alu repeats are randomly distributed. The difference between the observed value $3 / 19$ and the expected values ranging from $0.57 / 19$ to $0.95 / 19$ is of doubtful significance $(P=0.055$ to 0.123 by the binomial exact test), so at present we are unable to assess the general importance of the Alu sequences in generating nonhomologous deletions.

An interesting but probably unrelated finding in the normal $5^{\prime}$ sequence of $\gamma \delta \beta$-thal 1 is the occurrence of the hexanucleotide AATAAA followed by 18 A residues 126 bp $5^{\prime}$ to the breakpoint. This particular characteristic is shared by certain "processed" pseudogenes (Wilde et al., 1982a, 1982b; Lee et al., 1983). Work is in progress, using this sequence as a probe, to determine whether it is in fact the $3^{\prime}$ end of a processed pseudogene.

\section{The Relative Locations of the $5^{\prime}$ and $\mathbf{3}^{\prime}$ Breakpoints}

The lack of homology between the normal $5^{\prime}$ and $3^{\prime}$ DNA fragments of the two $\gamma \delta \beta$-thalassemia deletions makes it unlikely that DNA/DNA recognition was responsible for bringing these DNAs into proximity during the generation of the deletions. We therefore wondered whether the normal $3^{\prime}$ DNA in the $\beta$-globin gene cluster might for some other reason already be in close physical proximity to the normal $5^{\prime}$ non-globin DNA even though both are widely separated on the linear DNA map. We argued that if this were true then independent nonhomologous exchanges might occur more than once between elements of the $\beta$ globin gene cluster and the DNA sequences at this distant locality. For this reason we did an experiment to see whether the normal $5^{\prime}$ DNA corresponding to the $\gamma \delta \beta$-thal 2 deletion might be located close to the normal $5^{\prime}$ DNA corresponding to the $\gamma \delta \beta$-thal 1 deletion, just as their normal $3^{\prime}$ DNAs are close together in the $\beta$-globin gene cluster. Specifically, we took probe 2 (see Figure 1) spanning the deletion joint of $\gamma \delta \beta$-thal 2 and determined if it would hybridize to the phage clone, NORM. $5^{\prime}$, containing the normal $5^{\prime}$ DNA of the $\gamma \delta \beta$-thal 1 deletion. The result, referred to previously, was positive. This shows that the 
normal $5^{\prime}$ DNAs corresponding to these two large and independent deletions are indeed closely linked. Therefore in both cases the amount of DNA deleted is approximately the same, provided that they are not accompanied by more complex rearrangements.

Figure 3 presents the restriction map of the $14 \mathrm{~kb}$ insert of phage NORM. $5^{\prime}$, which includes the normal $5^{\prime}$ DNAs for both $\gamma \delta \beta$-thalassemias. Previously available genomic mapping data from the $\gamma \delta \beta$-thal 2 deletion case are consistent with this map. Thus Orkin et al. (1981), using Southern blots of genomic DNA, found Eco RI and Bgl II sites (marked with asterisks in Figure 1) at 2.8 and $5.0 \mathrm{~kb}$ on the $5^{\prime}$ side of the Hind III site immediately $5^{\prime}$ to the deletion joint. We found Eco RI and Bgl II sites 3.1 and 4.7 kb 5' to the Hind III site; they are also marked with asterisks in Figure 3.

We do not have any direct experimental data that establish the orientation of the map shown in Figure 3 with respect to the map of $\beta$-globin gene cluster, although a reasonable case can be made that this $14 \mathrm{~kb}$ DNA fragment normally lies on the $5^{\prime}$ side of the $\beta$-globin region so that the normal $5^{\prime}$ DNA of the $\gamma \delta \beta$-thal 1 is further from the $\beta$-cluster than is the normal $5^{\prime}$ DNA of the $\gamma \delta \beta$-thal 2 . The case rests primarily on the observations made by $V a n$ der Ploeg et al. (1980) and Orkin et al. (1981) which enabled these authors to deduce that the two cases are deletions rather than inversions. Specifically their DNA blotting data are consistent with the loss of the ${ }^{\mathrm{G}} \gamma,{ }^{\mathrm{A}} \gamma$, and $\delta$ globin genes, but are inconsistent with rearrangements that only change the positions of these genes. If the deletions are not accompanied by more complex rearrangements, then our sequence and mapping data are only compatible with the orientation described. However, we cannot exclude the possibility that the deletions are accompanied by other rearrangements, such as inversions.

The minimum lengths for the deletions can be estimated from experiments in progress ( $F$. Grosveld, unpublished data) in which cosmid clones have been used to extend the map of the human $\beta$-globin gene cluster in the $5^{\prime}$ and $3^{\prime}$ directions. At present, overlapping cosmid clones extending over $84 \mathrm{kp}$ in the $5^{\prime}$ direction from the $\beta$-globin gene have been isolated. None of these cosmid clones contain the restriction sites characteristic of the phage NORM. $5^{\prime}$, and none hybridize to DNA from the $5^{\prime}$ side of the two $\gamma \delta \beta$-thalassemia deletions. Consequently both the deletions must be over $90 \mathrm{~kb}$ in length ( $84 \mathrm{~kb} 5^{\prime}$ to $\beta+6$ $\mathrm{kb}$ of phage NORM. $5^{\prime}$ ). If we interpret the data in terms of simple deletions, then the lengths of these large deletions are within $4 \%$ of being identical. (The $5^{\prime}$ breakpoints are $6.5 \mathrm{~kb}$ apart; the $3^{\prime}$ breakpoints are $2.8 \mathrm{~kb}$ apart.)

\section{$5^{\prime}$ and 3' Breakpoints of Other Large Deletions}

The foregoing results establish that two independent $\gamma \delta \beta$ thalassemias associated with large deletions were produced by some mechanism that causes their $5^{\prime}$ breakpoints to be linked and in the same order as their $3^{\prime}$ breakpoints, with the $5^{\prime}$ breakpoints spaced approximately the same distance apart as the $3^{\prime}$ breakpoints. We therefore set out to determine if the same type of mechanism may act in producing other large deletions in the $\beta$-globin gene cluster, such as those associated with some cases of HPFH. Two types of HPFH chromosomes were available to us in which the deletions extend for large distances in the $3^{\prime}$ direction: one with the deletion breakpoint $11 \mathrm{~kb}$ to the $3^{\prime}$ side of the ${ }^{A} \gamma$-globin gene and the other with the deletion breakpoint $5 \mathrm{~kb}$ to the $3^{\prime}$ side of the ${ }^{A} \gamma$-globin gene (HPFH 1 and HPFH 2 respectively; see Tuan et al., 1980). If the type of mechanism responsible for the two $\gamma \delta \beta$-thalassemia deletions was also responsible for these two HPFH deletions, then one would expect the two HPFH deletions to have their corresponding $3^{\prime}$ breakpoints in normal DNA linked and in the same orientation as the normal $5^{\prime}$ breakpoints. The $3^{\prime}$ breakpoints should thus be approximately $6 \mathrm{~kb}(11 \mathrm{~kb}-5 \mathrm{~kb})$ apart. The rationale behind the method we used to test this prediction is represented diagrammatically in Figure 4.

The first three lines of Figure 4 summarize the simplest interpretation of our data from the two thalassemia cases. The top line shows normal DNA with JKLMNOPQ representing the $\beta$-globin gene cluster. The $\gamma \delta \beta$-thal 1 deletion is represented in the second line by a deletion of $G$ through $\mathrm{N}$, while the $\gamma \delta \beta$-thal 2 deletion in the third line is of 1 through $\mathrm{P}$. Using this notation, if we define the deletion in HPFH 2 as being $N$ through $W$, then the HPFH 1 deletion should be $\mathrm{O}$ through $V$ since we know from the literature that the $5^{\prime}$ breakpoint of HPFH 1 is $3^{\prime}$ to the $5^{\prime}$ breakpoint of HPFH 2 (Fritsch et al., 1979; Tuan et al., 1980; Bernards and Flavell, 1980). This prediction can be tested by blotting digests of DNA from suitable individuals with appropriate probes.

Two sources of DNA were used for our tests. DNA for the HPFH 2 deletion was from B. B., Sr., a black Ghanaian individual homozygous for HPFH 2 (Ringelhann et al., 1970; Fritsch et al., 1979; Tuan et al., 1980; Bernards and Flavell, 1980). DNA for the HPFH 1 deletion was from W. M., Jr. (Wheeler and Krevans, 1961; Charache and Conley, 1969; Fritsch et al., 1979), a black American whom we show here to be heterozygous for the HPFH 1 and HPFH 2 deletions. In order to test the prediction, we first needed

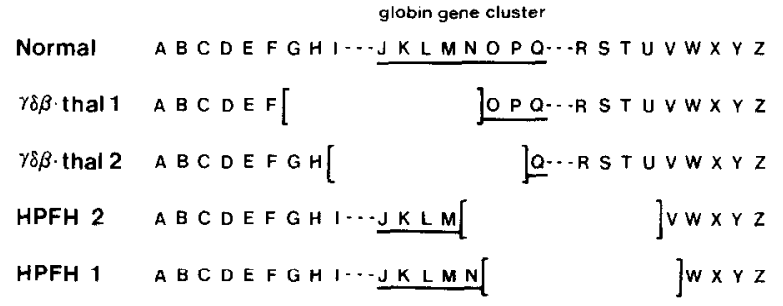

Figure 4. Schematic Representation of Normal DNA and the Deletions in $\gamma \delta \beta$-I halassemias 1 and 2 and HPFHs 1 and 2

Letters $A$ through $Z$ represent normal DNA; the $\beta$-globin gene is cluster undertined. The brackets surround the regions known or predicted to be deleted in the respective hemoglobinopathies. 
to clone a large (14 kb) Bam $\mathrm{Hl}$ fragment spanning the deletion in the HPFH 2 homozygote using as a probe (probe M) a $0.5 \mathrm{~kb}$ Bam Hl-Pvu II fragment from the second intervening sequence of the $A_{\gamma}$-globin gene. From the $14 \mathrm{~kb}$ Bam Hl fragment we then prepared a small $3^{\prime}$ terminal $1.1 \mathrm{~kb}$ Sst I-Bam HI fragment for use as a probe. We found that this probe also reacts with the HPFH 1 deletion chromosome and detects a $13 \mathrm{~kb}$ fragment in a Bam HI digest (see Figure 6 below). Accordingly, we can call the $14 \mathrm{~kb} \mathrm{Bam} \mathrm{HI}$ fragment from HPFH 2 "MVW" and the $1.1 \mathrm{~kb}$ Sst I-Bam HI fragment "W." A $1.6 \mathrm{~kb} \mathrm{Sst} \mathrm{I-Sst} \mathrm{I}$ fragment immediately $5^{\prime}$ to fragment $W$ was then prepared from the HPFH 2 clone $M V W$, and was tested on HPFH 1 DNA. It did not hybridize to the $13 \mathrm{~kb}$ Bam $\mathrm{H}$ fragment from HPFH 1 , and therefore has the predicted properties of probe $V$. For the normal $5^{\prime}$ DNAs we confirm the relationships suggested by the work of previous investigators (Fritsch et al., 1979; Tuan et al., 1980; Bernards and Flavell, 1980). Thus the RIH fragment of Fritsch et al. $(1979,1980)$ behaves as expected for a probe corresponding to $\mathrm{N}$-it hybridizes to the $13 \mathrm{~kb} \mathrm{Bam} \mathrm{Hl}$ fragment from HPFH 1 but not to the $14 \mathrm{~kb}$ Bam Hl fragment from HPFH 2. Probe $M$ hybridizes to both of the Bam $H$ ll fragments. The deletions therefore have the predicted relationships, with fragments $M V W$ and MNW being present respectively in $\mathrm{HPFH} 2$ and $\overline{\mathrm{HPFH}} 1$.

Figure 5 shows the maps and summarizes the hybridization results for the normal and the HPFH 1 and 2 chromosomes. Figure 6 presents the actual hybridization data for Southern transfers (Southern, 1975) of Bam HI digests of DNA from a normal individual, from an HPFH 2 homozygote (B. B., Sr.), and from an HPFH 1/HPFH 2 heterozygote (W. M., Jr.). Some comments are required on these experiments. First, since W. M., Jr. is a heterozygote, both the $13 \mathrm{~kb}$ MNW and the $14 \mathrm{~kb}$ MVW Bam HI fragments are present in his DNA. Second, because probe $M$ also reacts with the ${ }^{\mathrm{G}} \gamma$ gene, an additional $5 \mathrm{~kb}$ Bam HI fragment is detected by this probe in all three DNA samples. Third, the difference in length of the 13 and $14 \mathrm{~kb}$ Bam HI fragments from HPFH 2 and HPFH 1 tells us that

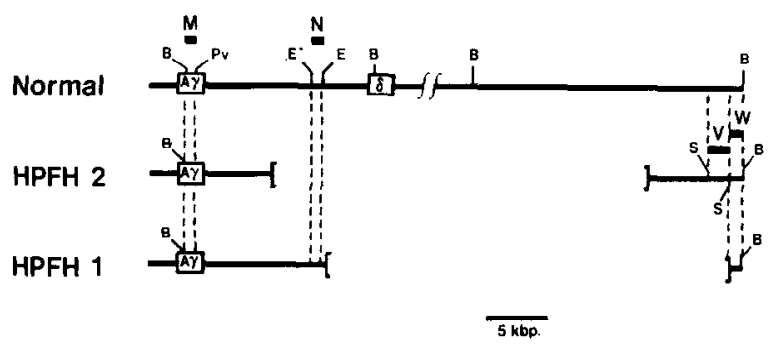

Figure 5. Summary of the Genomic Mapping Data for the HPFH 1 and HPFH 2 Deletions

The boxes represent the ${ }^{A} \gamma$ - and $\delta$-globin genes. The probes used (see text and Figure 6 ) are indicated by solid bars above the DNA from which they were isolated. The brackets encompass the deleted DNA and the vertical dashed lines are for orientation purposes. The restriction enzyme sites are: B, Bam HI; Pv, Pvu II; E, Eco Rl; S, Sst I. The E* is an Eco Rl site introduced during the cloning of the normal DNA (Fritsch et al., 1979, 1980). the distance between their $3^{\prime}$ breakpoints is within about $1 \mathrm{~kb}$ of the distance between their $5^{\prime}$ breakpoints.

These experiments demonstrate that the two HPFH deletions have their $3^{\prime}$ breakpoints linked in normal DNA and in the same orientation as the $5^{\prime}$ breakpoints, and that the amount of DNA deleted in these two HPFH cases is the same within $1 \mathrm{~kb}$. Tuan and coworkers (Tuan et al., 1983) have observed this same relationship between a different HPFH 1-type case (Tuan et al., 1980) and the same homozygous HPFH 2 case (Ringelhann et al., 1970) we have used here. We are currently investigating a case of ${ }^{G} \gamma^{+}\left({ }^{A} \gamma \delta \beta\right)^{0}$-thalassemia (Jones et al., 1981b) that also shows its $5^{\prime}$ and $3^{\prime}$ breakpoints in the expected order (D. Mager, personal communication).

Although we do not know how much DNA has been deleted in our two HPFH cases, we can set a lower limit on that value. Overlapping cosmid clones extending over $35 \mathrm{~kb}$ in the $3^{\prime}$ direction from the adult $\beta$-globin gene have been obtained ( $F$. Grosveld, unpublished data) and none of them hybridizes to probe $W$. The deletions must therefore be more than $50 \mathrm{~kb}$ ( $35 \mathrm{~kb}$ plus $15 \mathrm{~kb}$ between the $5^{\prime}$ end of the HPFH 2 deletion and the $\beta$-globin gene). Again, if we interpret the data in terms of simple deletions, then the lengths of the large deletions are within $2 \%$ of being identical.

\section{Possible Mechanisms}

The data presented establish that the $5^{\prime}$ breakpoints in the two cases of $\gamma \delta \beta$-thalassemia are located approxi-
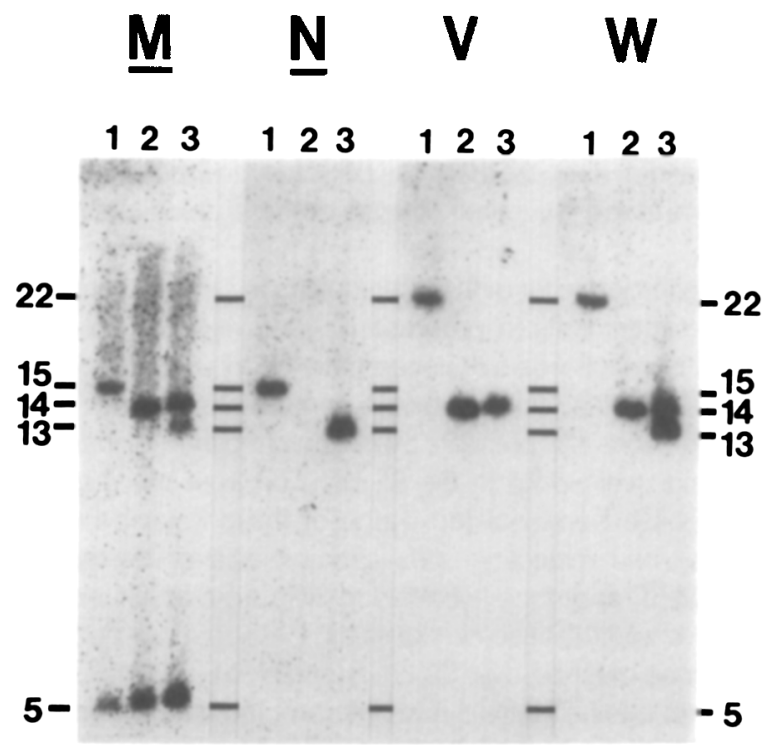

Figure 6. Southern Blots of Genomic DNA trom HPFH 1 and HPFH 2 All genomic DNAs were digested with Bam $\mathrm{Hl}$, electrophoresed on the same $0.8 \%$ agarose gel, and blotted to the probes $M, N, V$, and $W$. Lanes 1 are DNA from a normal fibroblast culture, lanes 2 are DNA from the HPFH 2 homozygote, and lanes 3 contain DNA from the heterozygote for HPFH $1 / \mathrm{HPFH}$ 2. The probes $\underline{M}, \underline{N}, V$ and $W$ are described in the text and illustrated in Figure 5. Fragments detected in these DNAs are 22, 15, 14, 13 , and $5 \mathrm{~kb}$, as indicated. The 22,15 , and $5 \mathrm{~kb}$ fragments are found in normal (nonrearranged) DNA, the $13 \mathrm{~kb}$ fragment is in HPFH 1 DNA and the $14 \mathrm{~kb}$ fragment is in HPFH 2 DNA. 
mately the same distance apart and in the same order along the DNA as their respective $3^{\prime}$ breakpoints; no homology could be detected between the normal DNA sequences located at the breakpoints. The same relationship is found between the breakpoints of two cases of HPFH also associated with large deletions. The data suggest, but do not unambiguously establish, that the deletions arc simple linear deletions. If they are, then each pair of deletions is of approximately the same length, although the thalassemia pair and the HPFH pair could be of different lengths. The question therefore arises as to possible mechanisms that might cause these independent large deletions to have DNA breakpoints related in these ways.

We suggest that these relationships may be the result of the close physical location of the normal $5^{\prime}$ and $3^{\prime}$ DNAs, perhaps because of their anchorage to some cellular structure. Loops of chromatin associated with points of anchorage to the nuclear matrix have been described by a number of different laboratories (Paulson and Laemmli, 1977; Marsden and Laemmli, 1979; Pardoll et al., 1980; Vogelstein et al., 1980) on the basis of several different lines of evidence. Loss of a complete loop in any particular deletion incident could account for our findings provided that the loops are of approximately equal size in any specified chromosomal region. The variation of the actual positions of the breakpoints (in contrast to their spacing) in the different cases implies either that the anchorage points are not uniquely sequence-specific or that the breakages occur while the DNA is being moved through the anchorage points, perhaps during replication (Pardoll et al., 1980). Since chromosomal rearrangements occur most readily during the $S$ through $G 2$ period (Rieger and Michaelis, 1967) it seems most likely that these large deletions arose as a consequence of a breakage event at a replication fork associated with one anchorage point, which was repaired by reunion to a replication fork at a nearby anchorage point, with the elimination of an integral

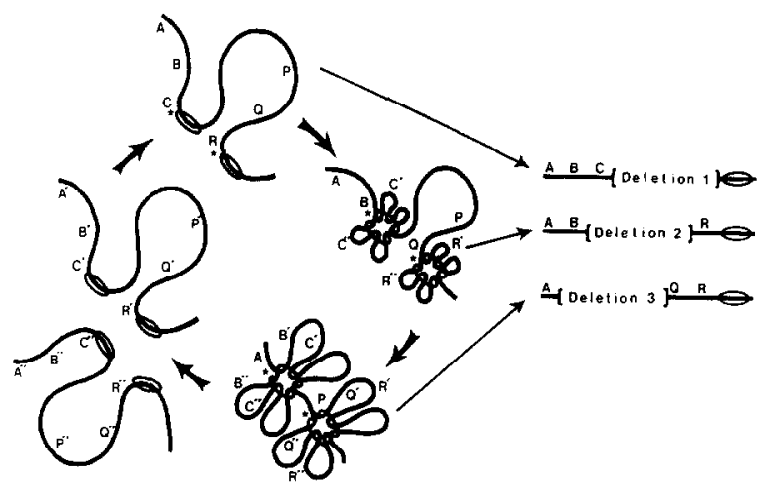

Figure 7. A Hypothetical Mechanism for the Formation of Related Deletions by the Loss of a Chromatin Loop at Different Slages of the Replication Cycle

Six sites are indicated by the letters $A B C$ and $P Q R$ before replication, and by $A^{\prime}, A^{\prime \prime}, B^{\prime}, B^{\prime \prime}$ etc. after one round of replication. Breakage and reunion events, at the places indicated by asterisks, form the related deletions 1 , 2 , and 3 (see text). The ellipses represent anchorage points and their associated replication complexes. number of chromatin loops. The net effect of this breakage and reunion event is to delete the DNA between adjacent replication forks. Depending on the stage of replication at the two forks, or variation between individuals in the location of the origins of replication, the "frame" of the deletion would appear to be shifted along the DNA in different examples of these large deletions, although their sizes would remain nearly constant. We do not, howcver, exclude the possibility that the deletions might occur by loss of a chromatin loop at a stage of the cell cycle other than the S-period. Figure 7 illustrates these various hypothetical possibilities. Deletion 1 is generated outside the S-period by loss of a chromatin loop following a simple breakage and reunion event at anchorage points; deletions 2 and 3 are generated by breakage and union events at replication forks.

\section{Experimental Procedures}

\section{Materials}

$\gamma^{32}$ P.ATP $(5000 \mathrm{Ci} / \mathrm{mmole}), \alpha^{32} \mathrm{P}$-dCTP and TTP $(800 \mathrm{Ci} / \mathrm{mmole})$ were from the Radiochemical Centre, Amersham. The $3^{\prime}$ end labeling kit was purchased from New England Nuclear. The calf intestinal alkaline phosphatase was from Boehringer Mannheim. All other enzymes were from either New England BioLabs or Bethesda Research Laboratories and were used as recommended by the manufacturer. The chemicals used in sequencing were as suggested by Maxam and Gilbert (1980).

\section{Sources}

Normal DNA was isolated from a normal fibroblast culture ( 563 from Dr. R DeMars). HPFH 2 DNA was isolated from GM2064, a cell line established from B. B., Sr., an HPFH 2 homozygote. DNA from W. M., Jr., a heterozygote for HPFH 1/HPFH 2, was also isolated from a fibroblast culture.

\section{Genomic Southem Blotting and Hybridizations}

Digests of genomic DNA were electrophoresed in $0.8 \%$ agarose gels. The gels were then treated essentially as described by Southern (1975) except that before denaturation the gels were soaked in $0.1 \mathrm{M} \mathrm{HCl}$ for $30 \mathrm{~min}$ in order to enhance the transfer of larger fragments.

After overnight transfer the filters were baked at $68^{\circ} \mathrm{C}$ for a minimum of $2 \mathrm{hr}$. The hybridization buffer used in the following steps (3X SSC, $0.1 \%$ SDS, $0.02 \mathrm{M}$ sodium phosphate buffer [pH 6.8], 0.2\% Ficoll [type 400], $0.2 \%$ polyvinylpyrrolidone [av. MW 360,000 ] $0.2 \% \mathrm{BSA}$, and $50 \mu \mathrm{g} / \mathrm{ml}$ of poly $(A)$ is a modified version of that used by Jeffreys and Flavell (1977). Before hybridization the filters were washed in hybridization buffer at $68^{\circ} \mathrm{C}$ for a minimum of $1.5 \mathrm{hr}$. The filters were then transfered to fresh hybridization solution, containing $2 \times 10^{6} \mathrm{cpm} / \mathrm{ml}$ of denatured nick-translated probe and $50 \mu \mathrm{g} / \mathrm{ml}$ of denatured, sonicated salmon sperm DNA. The hybridizations were alluwed to proceed at $68^{\circ} \mathrm{C}$ for $16-24 \mathrm{hr}$. Following hybridization the filters were washed in $3 X$ SSC containing $0.5 \%$ SDS.

All other hybridizations were done in $6 \times$ SSC containing $0.2 \%$ Ficoll $0.2 \%$ polyvinylpyrrolidone, $0.2 \%$ BSA, $0.5 \%$ SOS, $3-6 \times 10^{4} \mathrm{cpm} / \mathrm{ml}$ of denatured nick-translated probe and $50 \mu \mathrm{g} / \mathrm{ml}$ of poly $\mathrm{rA}$.

\section{DNA Sequencing}

Sequencing was performed as described by Maxam and Gilbert (1980) using the modifications of Slightom et al. (1980). Prior to sequencing, the appropriate fragments were subcloned into PAT153 (Twigg and Sherratt, 1980). All sequences were read from 5 ' end labelings with the exception of the sequences $200 \mathrm{bp}$ to elther side of an Sph I site $200 \mathrm{bp}$ into the quoted deletion breakpoint sequence which was also read from a $3^{\prime}$ end labeling. For the sequences reported here (the normal $5^{\prime}$ sequence for both $\gamma \delta \beta$-thalassemias, and the deletion breakpoint sequence for $\gamma \delta \beta$-thal 1) about two thirds of the regions were sequenced in both directions with overlaps. The remaining one third was sequenced at least twice on the same DNA strand. 
The sequence reported by Orkin et al. (1981) for the $\gamma \delta \beta$-thal 2 deletion breakpoint was confirmed and additional sequence data were obtained from this patient. These regions were only sequenced once, but the additional sequence is identical to the corresponding segment from the normal $5^{\prime}$ sequence.

In Figure 2 the normal $5^{\prime}$, deletion breakpoint and normal $3^{\prime}$ sequences for $\gamma \delta \beta$-thal 1 correspond to the complete sequences of the $0.8 \mathrm{~kb}$ Eco $R$ fragment (see Figure 3), the $0.5 \mathrm{~kb}$ Eco RI-Bam HI fragment (see Figure 1) and the Hind III-Bam HI fragment located approximately $2.5 \mathrm{~kb} 5^{\prime}$ to the $\beta$ globin gene respectively. These sequences for $\gamma \delta \beta$-thal 2 are the complete sequence of the $0.35 \mathrm{~kb}$ Hind III fragment (see Figure 3) as well as $0.35 \mathrm{~kb}$ of sequence $5^{\prime}$ to it, the Hind III-Bam HI fragment (Figure 1, probe 2) and part of the $\beta$-globin gene sequence (Lawn et al., 1980).

\section{Sequence Analysis}

DNA sequences were analyzed using software provided by the University of Wisconsin Genetics Computer Group.

\section{Acknowledgments}

We are especially grateful to Dr. S. Orkin for sending us his clone spanning the deletion breakpoint of $\gamma \delta \beta$-thal 2 as well as genomic DNA from the affected individual. We are grateful to $\mathrm{Dr}$. R. Spritz for communicating the unpublished normal $3^{\prime}$ sequence of $\gamma \delta \beta$-thal 1 , to Dr. G. Dover for sending us the fibroblast cell line from W. M., Jr., and to Dr. R. Demars for giving us the normal fibroblast cell line. We thank Natalie Borenstein and James B. Bliska for help with cultures and DNA. We also thank James Bardwell, James Nimock, Karen Lyons, and Stan Metzenberg for help in screening experiments.

We are also grateful to the members of our laboratory for helpful discussion and encouragement with a special thank you to Dr. D. Mager.

Finally we thank Frances Mann and Carol Jokinen for their efforts in typing this manuscript.

This work has been supported by National Institutes of Health grants (GM20069 and AM20120), by the Medical Research Council, and by a long term EMBO fellowship to D. K. This article is paper number 2693 from the Laboratory of Genetics, University of Wisconsin.

The costs of publication of this article were defrayed in part by the payment of page charges. This article must therefore be hereby marked "advertisement" in accordance with 18 U.S.C. Section 1734 solely to indicate this fact.

\section{Received September 14, 1983}

\section{Relerences}

Baglioni, C. (1962). The fusion of two peptide chains in hemoglobin Lepore and its interpretation as a genetic deletion. Proc. Nat. Acad. Sci. USA 48, 1880-1886.

Bernards, R., and Flavell, R. A. (1980) Physical mapping of the globin gene deletion in hereditary persistence of foetal haemoglobin (HPFH). Nucl. Acids Res. 8, 1521-1534.

Charache, S., and Conley, C. L. (1969). Hereditary persistence of fetal hemoglobin. Annals New York Acad. of Sci. 165, 37-41.

Deininger, P. L., Jolly, D. J., Rubin, C. M., Friedmann, T., and Schmid, C $W$. (1981). Base sequence studies of 300 nucleotide renatured repeated human DNA clones. J. Mol. Biol. 151, 17-33

Duncan, C. H., Jagadeeswaran, P., Wang, R. R. C., and Weissman, S. M. (1981). Structural analysis of templates and RNA polymerase III transcripts of Alu family sequences interspersed among the human $\beta$-like globin genes. Gene 13, 185-196.

Flavell, R. A., Kooter, J. M., De Boer, E., Little, P. F. R., and Williamson, R. (1978). Analysis of the $\beta$ - $\delta$-globin gene loci in normal and Hb Lepore DNA: direct determination of gene linkage and intergene distance. Cell 15, 2541.

Fritsch, E. F., Lawn, R. M., and Maniatis, T. (1979). Characterisation of deletions which affect the expression of fetal globin genes in man. Nature $279,598-603$.
Fritsch, E. F., Lawn, R. M., and Maniatis, T. (1980). Molecular cloning and characterization of the human $\beta$-like glouin gene cluster. Cell 19, 959-972. Gilman, J. G., and Huisman, T. H. J. (1983). The Dutch type of $\beta^{\circ}$ thalassaemia is due to a 10 kilobase deletion of DNA. Brit. J. Haemat., in press.

Houck, C. M., Rinehart, F. P., and Schmid, C. W. (1979). A ubiquitous family of repeated DNA sequences in the human genome. J. Mol. Biol. $132,289-306$.

Jagadeeswaran. P., Tuan, D., Forget, B. G., and Weissman. S. M. (1982). $A$ gene deletion ending at the midpoint of a repetitive DNA sequence in one form of hereditary persistence of fetal haemoglobin. Nature $296,469-$ 470 .

Jeffreys, A. J., and Flavell, R. A. (1977). A physical map of the DNA regions flanking the rabbit $\beta$-globin gene. Cell 12, 429-439.

Jelinek, W. R., Toomey, T. P., Leinwand, L., Duncan, C. H., Biro, P. A., Choudary, P. V., Weissman, S. M., Rubin, C. M., Houck, C. M., Deininger, P. L., and Schmid, C. W. (1980). Ubiquitous, interspersed repeated sequences in mammalian genomes. Proc. Nat. Acad. Sci. USA 77, 13981402.

Jones, R. W., Old, J. M., Trent, R. J., Clegg, J. B., and Weatherall, D. J. (1981a). Major rearrangement in the human $\beta$-globin gene cluster. Nature 291, 39-44.

Jones, R. W., Odd, J. M., Trent, R. J., Clegg, J. B. and Weatherall, D. J. (1981b). Restriction mapping of a new deletion responsible for ${ }^{6} \gamma(\delta \beta)^{0}$. thalassaemia. Nucl. Acids Res. 9, 6813-6825.

Kan, Y. W., Forget, B. G., and Nathan, D. G. (1972). Gamma-beta thalassemia: a cause of hemolytic disease of the newborn. New Engl. J. Med. 286, 129-134.

Kioussis, D., Vanin, E. F., De Lange, T., Favell, R. A., and Grosveld, F. G. (1983). $\beta$-globin gene inactivation by DNA translocation in $\gamma \beta$ thalassaemia. Nature, in press.

Lawn, R. M., Eistratiadls, A., O'Connell, C., and Maniatis, T. (1980). The nucleotide sequence of the human $\beta$-globin gene. Cell 21, 647-651.

Lee, M. G.S., Lewis, S. A., Wilde, C. D., and Cowan, N. J. (1983). Evolutionary history of a multigene family: an expressed human $\beta$-tubulin gene and three processed pseudogenes. Cell 33, 477-487.

Marsden, M. P. F., and Laemmii, U. K. (1979). Metaphase chromosome structure: evidence for a radial loop model. Cell 17, 849-858.

Maxam, A. M. and Gilbert, W. (1980). Sequencing end-labeled DNA with base-specific chemical cleavages. Meth. Enzymol. 65, 499-560.

Ohta, Y., Yamaoka, K., Sumida, I., and Yanase, T. (1971). Haemoglobin Miyada, a $\beta-\delta$ fusion peptide (anti-Lepore) type discovered in a Japanese family. Nature New Biol. 234, 218-219.

Orkin, S. H., Gotf, S. C., and Nathan, D. G. (1981). Heterogeneity of DNA deletion in $\gamma \delta \beta$-thalassemia. J. Clin. Invest. $67,878-884$.

Orkin, S. H., and Michelson, A. (1980). Partial deletion of the $\alpha$-globin structural gene in human $\alpha$-thalassaemia. Nature 286, 538-540.

Ottolenghi, S., and Giglioni, B. (1982). The deletion in a type of $\delta^{0}-\beta^{0}$. thalassaemia begins in an inverted Alu I repeat. Nature 300, 770-771.

Pan, J., Elder, J. T., Duncan, C. H., and Weissman, S. M. (1981). Structural analysis of interspersed repetitive polymerase III transcription units in human DNA. Nucl. Acids Res. 9, 1151-1170.

Pardoll, D. M., Vogetstein, B., and Coffey, D. S. (1980). A fixed site of DNA replication in eucaryotic cells. Cell 19, 527-536.

Paulson, J. R., and Laemmli, U. K. (1977). The structure of histone-depleted metaphase chromosomes. Cell 12, 817-828

Proudfoot, N. J., and Brownlee, G. G. (1976). $3^{\prime}$ non-coding region sequences in eukaryotic messenger RNA. Nature 263, 211-214.

Rieger, R., Michaelis, A. (1967). Die Chromosomenmutationen, VEB Gustav Fischer Verlag, Jena.

Ringelhann, B., Konotey-Ahnulu, F. I. D., Lehmann, H., and Lorkin, P. A. (1970). A Ghanaian adult, homozygous for hereditary persistence of foetal haemogiobin and heterozygous for elliptocytosis. Acat Haemat. 43, 100110.

Slightom, J. L., Blechl, A. E., and Smithies, O. (1980). Human fetal ${ }^{G} \boldsymbol{\gamma}$ - and 
${ }^{A} \gamma$-globin genes: complete nucleotide sequences suggest that DNA can be exchanged between these duplicated genes. Cell 21, 627-638.

Southern, E. M. (1975). Detection of specific sequences among DNA fragments separated by gel electrophoresis. J. Mol. Biol. 98, 503-517

Tuan, D., Feingold, E., Newman, M., Weissman, S. M., and Forget, B. G. (1983). Different $3^{\prime}$-endpoints of deletions causing $\delta \beta$-thalassemia and hereditary persistence of fetal hemoglobin: implications for the control of $\gamma$-globin gene expression in man. Proc. Nat. Acad. Sci. USA, in press.

Tuan, D., Murnane, M. J., deRiel, J. K., and Forget, B. G. (1980). Hetero geneity in the molecular basis of hereditary persistence of fetal haemoglobin. Nature 285, 335-337.

Twigg, A. J., and Sherratt, D. (1980). Trans-complementable copy-number mutants of plasmid ColE1. Nature 283, 216-218.

Van der Ploeg, L. H. T., Konings, A., Oort, M., Roos, D., Bernini, L., and Flavell, R. A. (1980), $\boldsymbol{\gamma}$ - $\beta$-thalassaemia studies showing that deletion of the $\gamma$ - and $\delta$-genes influences $\beta$-globin gene expression in man. Nature 283 , 637-642.

Vogelstein, B., Pardoll, D. M., and Coffey, D. S. (1980). Supercoiled loops and eucaryotic replication. Cell 22, 79-85.

Wheeler, J. T., and Krevans, J. R. (1961). The homozygous state of persistent fetal hemogiobin and the interaction of persistent fetal hemoglobin with thalassemia. Bull. Johns Hopkins Hosp. 109, 217-233.

Wilde, C. D., Crowther, C. E., Cripe, T. P., Lee, M. G.-S. and Cowan, N. J. (1982a). Evidence that a human $\beta$-tubulin pseudogene is derived from its corresponding mRNA. Nature 297, 83-84.

Wilde, C. D., Crowther, C. E., and Cowan, N. J. (1982b). Diverse mechanisms in the generation of human $\beta$-tubulin pseudogenes. Science 217 , 549-552. 